\title{
A DECISION SUPPORT MODEL FOR PASSENGER CAPACITY DESIGN OF BRT STATIONS
}

\author{
L. Engelbrecht ${ }^{1} \& \mathrm{~J}$. Bekker $^{2 *}$ \\ Department of Industrial Engineering \\ Stellenbosch University, South Africa \\ 1elouise@sun.ac.za; ${ }^{2}$ jb2@sun.ac.za
}

\begin{abstract}
In this paper, a decision support model for capacity planning of bus rapid transit stations is proposed. Static, deterministic models are used at present for station capacity design, whereas bus passenger flow through stations is dynamic with an associated stochastic element. Passenger arrivals vary over time, and are driven by bus schedules and process variation. The proposed model produces capacity design curves for given input data sets and bus schedules, and assists the station designer without being prescriptive. A case study of model application to the proposed Thibault Station in Cape Town, South Africa, is presented.
\end{abstract}

\section{OPSOMMING}

'n Besluitsteunmodel vir kapasiteitsbeplanning van sneldiensbusstasies word in hierdie artikel voorgehou. Tans word statiese, deterministiese modelle gebruik vir stasiekapasiteitsontwerp, terwyl passasiersvloei deur busstasies dinamies is met 'n stochastiese element. Passasiersaankomste varieer oor tyd en word bepaal deur busskedules en prosesvariasie. Die voorgestelde model lewer kapasiteitontwerpkurwes vir gegewe insetdata en busskedules en ondersteun die stasieontwerper sonder om voorskriftelik te wees. Die toepassing van die model word geïllustreer met behulp van 'n gevallestudie by die beplande Thibault-stasie in Kaapstad, Suid-Afrika.

\footnotetext{
${ }^{1}$ The author was enrolled for an MSc Eng (Engineering Management) degree in the Department of Industrial Engineering at Stellenbosch University.

* Corresponding author
} 


\section{INTRODUCTION}

Traffic congestion has increased dramatically over the past two decades, threatening the economy of many developing countries and the quality of life of their citizens. Traffic congestion is defined as a phenomenon on transport networks that arises as use increases, and is characterised by slower travelling speeds, longer trip times, and increased queuing. It occurs when traffic demand is greater than the capacity of a road [12].

In 2003, the Texas Transportation Institute recorded that congestion in the top 85 urban areas in the United States had cost the country $\$ 3.7$ billion in travel delays, and resulted in 2.3 billion gallons of wasted fuel. Internationally, countries are searching for ways to decrease congestion on roads. This has led to the constant development of new technology, and to different congestion-management strategies being developed and tested worldwide. Some include high-occupancy vehicle (HOV) lanes, congestion pricing, carpooling, vanpooling, ridesharing, bikeways, transit lanes, and various modes of public transport - the last being the prevalent congestion-relieving alternative. Public transport in which city management could invest includes metro rail, light rapid transit (LRT), monorail, suburban rail, standard bus systems, and bus rapid transit (BRT) systems (Wright \& Hook [14]). This paper focuses on the last of those, the BRT system.

A BRT system is a high-capacity public transportation system that carries passengers from one point to another, providing a bus service that is faster and more efficient than an ordinary bus line. At present BRT systems are predominantly planned and designed according to a bus rapid transit planning guide developed by the Institute for Transportation and Development Policy (ITDP), whose head office is in New York (ITDP [4]). In this guide, the methods (Wright \& Hook [14]) used to calculate the capacity of a BRT system are based on deterministic equations that provide capacity measures for an entire BRT system. We identified the need to investigate the capacity parameters of a single bus station while considering dynamic, stochastic input.

In this paper, we describe the development of a decision support model for BRT system planners, designers, and managers that can assist with the planning and designing of BRT stations, particularly in relation to station capacity. The term 'capacity' refers to the ability of the station to host entering and departing bus passengers - i.e., the floor area required over time. We demonstrate how to estimate percentiles of the capacities, as percentiles afford the decision maker or designer more information than the classic estimated mean.

The importance of this work for the transportation industry is that:

- system planners and designers can use the model to investigate different scenarios and evaluate the impact of each in terms of cost, relieving congestion, and other environmental impacts;

- system planners and designers can use this model to assist with decision-making about the system sizing and capacity requirements of stations;

- the future costs of proposed systems can be estimated based on the projected performance of the simulation models; and

- system managers could use this tool to investigate an existing system to reveal problem areas as well as opportunities for improvement.

We first present some literature related to our study. This is followed by the problem description, a description of the model development using a real-world case study, and the results and conclusions. Finally, we discuss future research on this model.

\section{LITERATURE}

A literature review showed little information on BRT station capacity planning. The most extensive literature pertains to setting design standards (e.g. Highway Capacity Manual 
2000 [13], Transit Capacity and Quality of Service Manual (Kittelson \& Associates [5])). Pedestrians do not want to wait in dense crowds that cause limited and uncomfortable movement. Therefore standards and procedures were introduced to maintain a desirable pedestrian level of service. These standards and procedures for evaluating pedestrian capacity and levels of service are provided in the Transit Capacity and Quality of Service Manual (Kittelson \& Associates [5]) and in Pedestrian Planning and Design (Fruin [2]). Furthermore, relationships between pedestrian flow measures, such as speed, space, and delay, are contained in the Highway Capacity Manual 2000 [13].

Capacity planning of BRT systems focuses more on the corridor's capacity as a whole. The entire network is modelled so that the overall capacity of the system can be evaluated. BRT corridors are usually modelled with simulation, which can be classified according to the level of detail with which they represent the system: microscopic, mesoscopic, and macroscopic simulation (Lieberman \& Rathi [7]). The type of simulation model used depends on the required level of detailed analysis. A microscopic model describes the system entities and their interactions at a high level of detail. A mesoscopic model also describes most of the entities at a high level of detail, but their activities and interactions at a much lower level of detail. Macroscopic models describe the entities and their activities at a low level of detail; lane change manoeuvres, for example, would not be represented (Lieberman \& Rathi [7]). Examples of these traffic simulation models used on corridors include NETSIM (microscopic), NETFLO (mesoscopic), TRANSYT-7F, SYNCHRO, and CORFLO (macroscopic) (Sabra et al. [9]). These traffic simulation models do not take passenger flow into account, and instead see bus stations as a 'delay' in the entire corridor. This was one of our reasons for investigating the passenger capacity of a single bus station.

We propose estimating percentiles for the capacities, as these are more informative than estimated means. If $X$ has the cumulative distribution function $F(X)$, the $p$-percentile is defined as $F(p)=P(X \leq p)=q$. In most courses in elementary statistics, students are only taught to do inferences based on the mean. This is inadequate, because in practical situations it is often necessary (and sensible) to estimate percentiles of a system performance parameter. A simple example is the required volume of a buffer tank, given a stochastic inflow and outflow of, say, water. Assume the tank is a cylinder with a fixed diameter; then the tank height must be determined to provide some buffer volume. Suppose the nett height due to the flow can be estimated via analytical methods, and the nett height is found to be gamma $(\alpha, B)$ distributed with $a=2$ and $B=3$. The mean is $a B=6$, and if the tank is designed for this value, it will overflow $40 \%$ of the time. If the designer wants the tank to absorb flow $95 \%$ of the time, the tank height should be 14.2 units.

Estimating percentiles is more difficult than estimating means, mainly due to data storage and sorting requirements. Research on this topic dates back to 1976 (Iglehart [3]; Seila [11]). Raatikainen [8] proposed a sequential procedure that requires no storing and sorting, but is difficult to implement. Chen \& Kelton [1] propose two heuristic sequential algorithms and apply these to delay queue processes. We present our percentile estimations in Section 6.

\section{PROBLEM OVERVIEW}

A primary objective of BRT system operations is to maximise passenger throughput. Factors that affect the speed and ease with which passengers travel throughout the system include rapid and efficient bus operations, adequate facilities, the physical layout of stations, and bus designs. Design parameters of a station that affect the station capacity include the inter-arrival times of passengers, the station layout, the number of bus parking bays or platforms, the number of disembarking and boarding passengers, bus capacities, and bus schedules. Capacity, measured in persons per hour per direction (pphpd), is currently calculated using simple deterministic equations that are accepted worldwide as the standard. Deterministic design parameter values derived from these equations are used to model the entire BRT system. However, the bus station can be considered a complex queuing system, as there are two processes for passenger arrivals and for departures. In the 
first arrival process, passengers arrive at the station on foot and are removed by buses, while in the second arrival process, random numbers of passengers are delivered to the station by bus and leave the station on foot. This is schematically shown in Figure 1.

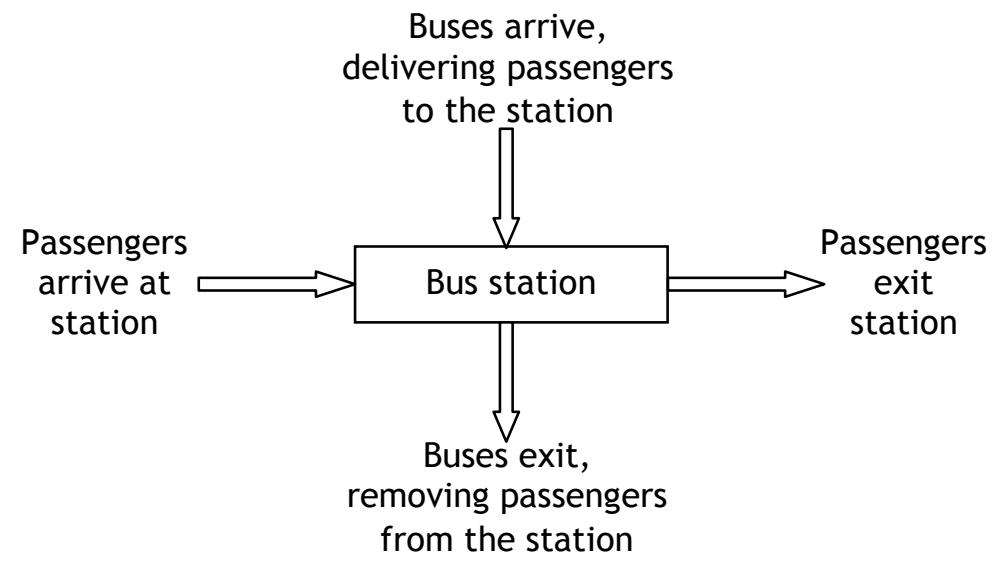

Figure 1: The bus station as a queuing system

During design, models are mainly used to investigate the flow of buses throughout the entire system. However, we identified the need to investigate the effects of these deterministic design parameter values on the capacity of a single bus station. Because these parameters are assigned predetermined, fixed values, any variation in the operations of a bus station is ignored, which is unrealistic. Therefore, it is necessary to investigate what effect these parameters will have on the capacity of a single bus station when introducing elements of variation. The variation is realised through pseudo-randomness and consequent stochastic modelling. An example of a random input is the number of passengers entering the station at some time during the day. This time-dependent event and others can be studied using a specific probability distribution to determine the number of passengers entering the station at that time of day. Considering these, we propose a dynamic, stochastic model to accommodate the time-dependent variation of the real-life system (bus station).

Next, a modelling case study of a real-life station is presented, which served to guide the model development and evaluate the resulting proposed stochastic modelling approach.

\section{CASE STUDY: THIBAULT STATION}

The study is based on Thibault Station, a bus station that forms part of the BRT system in Cape Town, South Africa. At the time of writing, Thibault Station was under construction. A stochastic model of Thibault Station was developed in which the random arrival of passengers and the scheduled arrival of buses were realised so that the impact on station capacity could be examined. The stochastic model is a time-dependent, discrete-event computer simulation model that allows for what-if questions and the replication of passenger arrivals using known input data. This stochastic model, together with an appropriate user interface, forms the proposed decision support model.

This section provides information on the system operations that were simulated for Thibault Station. A concept model that helps to plan the simulation model is presented, followed by an explanation of the model architecture and model functions.

\subsection{Concept model description}

Thibault Station is an enclosed bus station with glass sliding doors, staffed ticket booths, pre-board fare verification (by means of turnstiles), and four platforms. The operations of Thibault Station involve: 
Passenger arrivals and flow:

- There are two entrances to the station. Entrance 1 is the main entrance where passengers buy tickets from a ticket booth before proceeding to the platforms where outgoing passengers embark and incoming passengers disembark. Entrance 2 , which does not have a ticket booth, is situated at the opposite end of the station. This entrance only allows access to passengers who already have a ticket. The majority of these passengers have monthly or season tickets, allowing them quicker access to the platforms. They can also enter through Entrance 1.

- Passengers verify their tickets at the turnstiles and then proceed to their desired platform waiting area.

Buses:

- The buses operate in a separate dedicated BRT bus lane, allowing little interference from other modes of traffic.

- Two routes depart from Thibault Station, with different types of buses serving each route. The T01 route uses bi-articulated buses with a passenger capacity of 120. The TO2 route uses smaller buses seating only 40 passengers.

- The buses operate according to a schedule; bus arrivals are thus considered to be deterministic.

- The fleet size is changed throughout the course of the day in accordance with variation in demand at various times during the day.

Infrastructure:

- The station has four platforms to facilitate passenger arrivals and departures.

- Platform 1 is allocated to T01 buses, and transfers passengers from various urban bus stations to the CBD of Cape Town. Platform 3 is also a T01-allocated platform, and routes out to Blaauwberg, approximately $30 \mathrm{~km}$ away in a northerly direction.

- TO2 buses stop at Platform 2 and proceed to the CBD. Platform 4, situated opposite Platform 2, is also a TO2-allocated bus stop, and transfers passengers to Cape Town international airport.

- There are two parking berths at each platform, allowing parking space for an additional bus waiting for the platform.

A schematic layout to explain the movement of the buses to and from their dedicated platforms, as well as the position of the platforms at Thibault Station, is shown in Figure 2. T01 buses follow the cycle represented by the broken lines, while TO2 buses follow the dotted lines. The two drop-off stations (A and B in Figure 2) are dummy stations, and were used in the model to represent all other stations that form part of a cycle. The cycle time of each bus on each route to these dummy stations was incorporated into the model, which ensures model validity.

The entities in the model are the passengers and the buses. These are the 'discrete units of traffic' in the simulation model, as stated by Schriber \& Brunner [10].

Model restrictions include:

- Vehicles operating between 04:00 and 23:00, every day of the week.

- T01 buses having a capacity of 120 passengers.

- $\quad$ TO2 buses having a capacity of 40 passengers.

- The number of boarding passengers can only be as large as the number of available seats on the particular bus. 


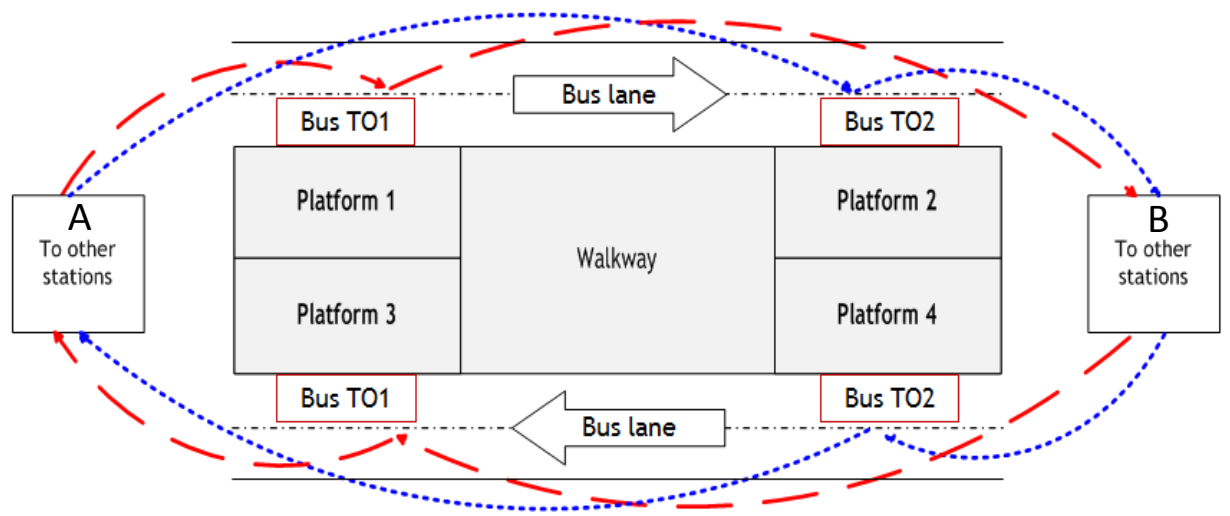

Figure 2: Schematic layout of Thibault Station

Model assumptions include:

- The various bus types always stop at their dedicated platforms. If buses arrive simultaneously at the same platform, or if one arrives while the parking berth is already occupied, that bus will stop behind the bus already occupying the designated parking berth to await its turn.

- Dwell, boarding, and disembarkation times are assumed to be incorporated into the passenger arrival times.

- Buses always arrive according to scheduled times.

- The bus capacities, already defined for the different types of buses, represent the passenger seating capacity, and are taken as the maximum number of passengers that the vehicle can accommodate. Standing passengers are not included in the model.

The concept model is based on the operations mentioned above, and was used to build the simulation model.

\subsection{Model architecture}

The decision support model has a user interface implemented in Microsof $\mathrm{t}^{\circledR}$ Excel, while the simulation package Arena of Rockwell Automation was used to implement the stochastic part of the model. A second interface between MS Excel and Arena made the user input available to Arena in the required format. This can be seen in Figure 3.

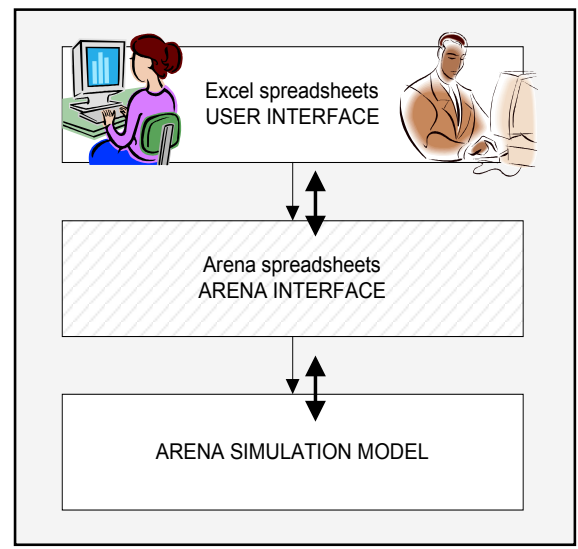

Figure 3: The interfaces used at different levels of operation 
The simulation model is built according to the operations specified in the concept model, and is aimed to assist with capacity planning at Thibault Station. Although this model is based on the operations of Thibault Station - i.e., Thibault's specific platform layout, bus schedule, passenger arrival rates, and so on - it is sufficiently generic to be applied and used at similar BRT stations.

The key functions of the simulation model are that:

- $\quad$ users are able to define input data for the model to suit the specifications of their station under investigation, and

- analysis of capacity parameters can be performed, and required station capacities can be predicted, from the model results.

The next section describes the functionality of the developed simulation model by presenting extracts of the 'user interface' spreadsheets.

\subsection{Model functionality}

The user interface spreadsheets, which are briefly explained below, allow users to define and change certain input data. The user interface spreadsheet shown in Figure 4 accepts passenger arrival data at Thibault Station. The data vary over the day in hourly resolution, and are expressed as a percentage of the daily maximum expected number of passenger arrivals.

\begin{tabular}{|c|c|c|c|c|c|c|c|c|c|c|c|c|}
\hline \multicolumn{4}{|c|}{ Passenger demand profiles } & \multirow{2}{*}{\multicolumn{4}{|c|}{$\begin{array}{l}\text { Users can change } \\
\text { these numbers }\end{array}$}} & & & & & \\
\hline \multicolumn{3}{|c|}{$\begin{array}{l}\text { Thibault Station at Full Capacity (Pph at Peak hour) } \\
\% \text { of station capacity of TO1 bus service } \\
\% \text { of station capacity of TO2 bus service }\end{array}$} & $\begin{array}{l}800 \\
80 \% \\
20 \%\end{array}$ & & & & & & & & & \\
\hline \multirow[t]{3}{*}{ Time of day } & \multicolumn{2}{|c|}{ \% Passenger estimates of full capacity } & \multicolumn{2}{|c|}{ Estimated number of passengers } & \multicolumn{4}{|c|}{$\%$ of TO1 passengers enter Ent1\&Ent2 to P1\&P3 } & \multicolumn{4}{|c|}{$\%$ of TO2 passengers enter Ent1\&Ent2 to P2\&P4 } \\
\hline & TO1 Busses & TO2 Busses & TO1 Busses & TO2 Busses & \multicolumn{2}{|c|}{ Entrance 1} & \multicolumn{2}{|c|}{ Entrance 2} & \multicolumn{2}{|c|}{ Entrance 1} & \multicolumn{2}{|c|}{ Entrance 2} \\
\hline & & & & & P1 & P3 & P1 & P3 & P2 & P4 & P2 & P4 \\
\hline 4-5am & $10 \%$ & $10 \%$ & 64 & 16 & $35 \%$ & $30 \%$ & $25 \%$ & $10 \%$ & $40 \%$ & $30 \%$ & $20 \%$ & $10 \%$ \\
\hline 5-6am & $30 \%$ & $30 \%$ & 192 & 48 & $35 \%$ & $30 \%$ & $25 \%$ & $10 \%$ & $40 \%$ & $30 \%$ & $20 \%$ & $10 \%$ \\
\hline 6-7am & $90 \%$ & $70 \%$ & 576 & 112 & $35 \%$ & $30 \%$ & $25 \%$ & $10 \%$ & $40 \%$ & $30 \%$ & $20 \%$ & $10 \%$ \\
\hline $7-8 a m$ & $100 \%$ & $90 \%$ & 640 & 144 & $35 \%$ & $30 \%$ & $25 \%$ & $10 \%$ & $40 \%$ & $30 \%$ & $20 \%$ & $10 \%$ \\
\hline 8-9am & $60 \%$ & $100 \%$ & 384 & 160 & $35 \%$ & $30 \%$ & $25 \%$ & $10 \%$ & $40 \%$ & $30 \%$ & $20 \%$ & $10 \%$ \\
\hline 9-10am & $30 \%$ & $100 \%$ & 192 & 160 & $35 \%$ & $30 \%$ & $25 \%$ & $10 \%$ & $40 \%$ & $30 \%$ & $20 \%$ & $10 \%$ \\
\hline $10-11 \mathrm{am}$ & \multirow{4}{*}{\multicolumn{2}{|c|}{$\begin{array}{l}\text { Users can change } \\
\text { these numbers }\end{array}$}} & 128 & 144 & $35 \%$ & $30 \%$ & $25 \%$ & \multirow{4}{*}{\multicolumn{3}{|c|}{$\begin{array}{l}\text { Users can change } \\
\text { these numbers }\end{array}$}} & $20 \%$ & $10 \%$ \\
\hline $11-12 \mathrm{pm}$ & & & 128 & 144 & $35 \%$ & $30 \%$ & $25 \%$ & & & & $20 \%$ & $10 \%$ \\
\hline $12-13 \mathrm{pm}$ & & & 192 & 128 & $35 \%$ & $30 \%$ & $25 \%$ & & & & $20 \%$ & $10 \%$ \\
\hline $13-14 \mathrm{pm}$ & & & 192 & 128 & $35 \%$ & $30 \%$ & $25 \%$ & & & & $20 \%$ & $10 \%$ \\
\hline $14-15 \mathrm{pm}$ & $30 \%$ & $80 \%$ & 192 & 128 & $35 \%$ & $30 \%$ & $25 \%$ & $10 \%$ & $40 \%$ & $30 \%$ & $20 \%$ & $10 \%$ \\
\hline $15-16 \mathrm{pm}$ & $30 \%$ & $90 \%$ & 192 & 144 & $35 \%$ & $30 \%$ & $25 \%$ & $10 \%$ & $40 \%$ & $30 \%$ & $20 \%$ & $10 \%$ \\
\hline $16-17 \mathrm{pm}$ & $60 \%$ & $100 \%$ & 384 & 160 & $35 \%$ & $30 \%$ & $25 \%$ & $10 \%$ & $40 \%$ & $30 \%$ & $20 \%$ & $10 \%$ \\
\hline $17-18 \mathrm{pm}$ & $100 \%$ & $100 \%$ & 640 & 160 & $35 \%$ & $30 \%$ & $25 \%$ & $10 \%$ & $30 \%$ & $30 \%$ & $20 \%$ & $20 \%$ \\
\hline $18-19 \mathrm{pm}$ & $80 \%$ & $90 \%$ & 512 & 144 & $35 \%$ & $30 \%$ & $25 \%$ & $10 \%$ & $40 \%$ & $30 \%$ & $20 \%$ & $10 \%$ \\
\hline $19-20 \mathrm{pm}$ & $40 \%$ & $80 \%$ & 256 & 128 & $35 \%$ & $30 \%$ & $25 \%$ & $10 \%$ & $40 \%$ & $30 \%$ & $20 \%$ & $10 \%$ \\
\hline $20-21 \mathrm{pm}$ & $10 \%$ & $70 \%$ & 64 & 112 & $35 \%$ & $30 \%$ & $25 \%$ & $10 \%$ & $40 \%$ & $30 \%$ & $20 \%$ & $10 \%$ \\
\hline $21-22 \mathrm{pm}$ & $10 \%$ & $50 \%$ & 64 & 80 & $35 \%$ & $30 \%$ & $25 \%$ & $10 \%$ & $40 \%$ & $30 \%$ & $20 \%$ & $10 \%$ \\
\hline $22-23 \mathrm{pm}$ & $10 \%$ & $10 \%$ & 64 & 16 & $35 \%$ & $30 \%$ & $25 \%$ & $10 \%$ & $40 \%$ & $30 \%$ & $20 \%$ & $10 \%$ \\
\hline Column & 1 & 2 & 3 & 4 & 5 & 6 & 7 & 8 & 9 & 10 & 11 & 12 \\
\hline
\end{tabular}

Figure 4: Passenger arrival specification spreadsheet

The user interface spreadsheet for the input data related to the arrival of buses is shown in Figure (part of the T01 route specification). An MS Excel spreadsheet was developed for each route, which also serves as a method of assigning the attributes to the arriving buses. The simulation model reads the 'expected' arrival times as constants, thus emulating the bus schedule.

\begin{tabular}{|c|c|c|c|c|c|c|c|c|c|}
\hline \multicolumn{10}{|c|}{$\begin{array}{l}\text { Bus Schedule TO1 } \\
\text { Using estimated cycle times to assign scheduled arrivals and fleet size }\end{array}$} \\
\hline \multirow[t]{2}{*}{$\begin{array}{c}\text { Daily } \\
\text { operating hour }\end{array}$} & \multirow[t]{2}{*}{ Bus freq/hr } & \multirow[t]{2}{*}{$\begin{array}{c}\text { Estimated cycle } \\
\text { times(Min) }\end{array}$} & \multirow[t]{2}{*}{$\begin{array}{c}\text { Assigned bus } \\
\text { number }\end{array}$} & \multicolumn{5}{|c|}{ Arrival times(min) at the different stations } & \\
\hline & & & & P1 & DO1 & P3 & DO2 & Arrival time back at P1 & \\
\hline \multirow[t]{4}{*}{$4-5$} & 3 & $80 \mathrm{~min}$ & & $00: 00$ & $00: 20$ & $00: 40$ & 01:00 & 01:20 & \\
\hline & & & 1 & 04:00 & $04: 20$ & $04: 40$ & 05:00 & $05: 20$ & 1 \\
\hline & & & 2 & $04: 20$ & 04:40 & 05:00 & $05: 20$ & $05: 40$ & 2 \\
\hline & & & 3 & $04: 40$ & 05:00 & $05: 20$ & $05: 40$ & $06: 00$ & 3 \\
\hline \multirow[t]{5}{*}{$5-6$} & 4 & $100 \mathrm{~min}$ & & 00:00 & $00: 25$ & $00: 50$ & 01:15 & 01:40 & \\
\hline & & & 4 & 05:00 & $05: 25$ & $05: 50$ & $06: 15$ & $06: 40$ & 4 \\
\hline & & & 5 & 05:15 & 05:40 & 06:05 & $06: 30$ & $06: 55$ & 5 \\
\hline & & & 1 & $05: 30$ & $05: 55$ & $06: 20$ & $06: 45$ & 07:10 & 1 \\
\hline & & & 2 & $05: 45$ & $06: 10$ & $06: 35$ & 07:00 & 07:25 & 2 \\
\hline
\end{tabular}

Figure 5: Snapshot of a T01 bus schedule 
Next, the number of passengers arriving by bus is assigned a random quantity less than bus capacity, which represents the number of passengers disembarking. This yields a secondary source of arrivals at the station, and also affects the station capacity.

The decision support model was built, verified, and validated to ensure the correctness and reasonableness of the model's functions and outcomes. A deterministic version of the model was most useful, since outcomes could be predicted based on known input.

The performance measurements provided by the model are:

- the percentiles of the number of passengers waiting and duration per station platform, and

- the average waiting time of the passengers.

These were all estimated using point estimators and $95 \%$ confidence intervals, according to the procedure of Law \& Kelton [6]. Some scenarios that were evaluated are described in the next section.

\section{EXAMPLE OF SCENARIOS}

To demonstrate the purpose and usefulness of the decision support model, two scenarios were constructed that differ in terms of their mean inter-arrival times of passengers entering the station. Scenario 1 is based on the original input data obtained from the station designer, while for Scenario 2 the passenger inter-arrival times were decreased by $25 \%$. This implies a higher arrival rate of passengers for Scenario 2, while the bus schedule and the number of buses allocated are maintained. These scenarios are used to show the various ways in which this model could be used to obtain system response information, as well as the consequences of decisions made.

We shall present two types of output: estimated means, and estimated percentiles of system performance measures. We introduced the idea of percentiles in Section 2, and here we briefly outline how we estimated the percentiles for this problem. The simulation package Arena allows for the specification of histograms as output, and can determine confidence intervals per histogram class, provided a sufficient number of simulation replications were executed. From the histogram counts it is possible to determine the percentage of time a parameter was at a certain level, and the percentiles can then be deduced from these results. One possible drawback of this approach is that the histogram classes must be specified beforehand (Seila [11]).

To illustrate the approach, we simulated an $M|M| 1$ queue with traffic intensity $\rho=0.9$. The number of entities in the system $X$ in steady state follows the geometric distribution $f(x)=\rho^{x}(1-\rho), x=0,1,2, \ldots$ These exact probabilities were calculated for the first 30 values of $X$ (0 to 29), and are shown as 'Exact $\operatorname{Pr}(\mathrm{x})$ ' in Table 1 . The column labelled 'Sum $\operatorname{Pr}(\mathrm{x})$ ' in the table is the exact cumulative distribution values for $X$. The simulated values are listed in the columns labelled 'Estim. $\operatorname{Pr}(\mathrm{x})$ ' and 'Sum Estim. $\operatorname{Pr}(\mathrm{x})$ '. The estimations are based on 5,000 pseudo-independent replications of 2,000 time units each, with 500 time units as warm-up. The absolute deviations ('Abs. Dev.') are reasonably small, so the simulation model is an acceptable estimator for the percentiles. It can, for example, be concluded from Table 1 that there will be 10 or fewer entities in the system with a probability of 0.69 . Note that the cumulative distribution is discontinuous in this case, due to the discrete nature of $X$.

Some scenario results for the Thibault Station design are presented next. 


\begin{tabular}{|c|c|c|c|c|c|c|c|c|c|c|c|}
\hline$x$ & $\operatorname{Pr}(\mathrm{x})$ & $\begin{array}{l}\text { Sum } \\
\operatorname{Pr}(\mathrm{x})\end{array}$ & $\begin{array}{l}\text { Estim. } \\
\operatorname{Pr}(\mathrm{x})\end{array}$ & $\begin{array}{l}\text { Sum } \\
\text { Estim. } \\
\operatorname{Pr}(\mathrm{x})\end{array}$ & $\begin{array}{l}\text { Abs. } \\
\text { Dev. }\end{array}$ & $x$ & $\begin{array}{r}\text { ract } \\
\mathrm{r}(\mathrm{x})\end{array}$ & $\begin{array}{l}\mathrm{um} \\
\mathrm{r}(\mathrm{x})\end{array}$ & $\begin{array}{l}\text { Estim. } \\
\operatorname{Pr}(\mathrm{x})\end{array}$ & $\begin{array}{l}\text { Sum } \\
\text { Estim. } \\
\operatorname{Pr}(\mathrm{x})\end{array}$ & $\begin{array}{l}\text { Abs. } \\
\text { Dev. }\end{array}$ \\
\hline 0 & 0.100 & .100 & 0.100 & 0.100 & 0.000 & 15 & 0.021 & 0.815 & 0.021 & 0.816 & 0.017 \\
\hline 1 & 0.090 & 0.190 & 0.090 & 0.190 & 0.002 & 16 & 0.019 & 0.833 & 0.019 & 0.835 & 0.018 \\
\hline 2 & 0.081 & 0.271 & 0.081 & 271 & 0.002 & 7 & 0.017 & 850 & 17 & .852 & 0.020 \\
\hline 3 & 0.073 & 0.344 & 0.073 & 344 & 0.001 & 8 & 0. & 865 & 15 & .867 & 0.021 \\
\hline 4 & 0.066 & 0.410 & 0.065 & 409 & 0.001 & 19 & 0.0 & .878 & .014 & .881 & 0.021 \\
\hline 5 & 0.059 & 0.469 & 0.059 & 468 & 0.001 & 20 & 0.01 & 0.891 & 0.012 & 0.893 & 0.021 \\
\hline 6 & 0.053 & 0.522 & 0.053 & 0.522 & 0.001 & 21 & 0.011 & 0.902 & 0.011 & 0.904 & 0.021 \\
\hline 7 & 0.048 & 0.570 & 0.048 & 0.570 & 0.000 & 22 & 0.010 & 0.911 & 0.010 & 0.913 & 0.020 \\
\hline 8 & 0.043 & 0.613 & 0.043 & 0.613 & 0.001 & 23 & 0.009 & 0.920 & 0.009 & 0.922 & 0.020 \\
\hline 9 & 0.039 & 0.651 & 0.039 & 0.652 & 0.003 & 24 & 0.008 & 0.928 & 0.008 & 0.930 & 0.019 \\
\hline 10 & 0.035 & 0.686 & 0.035 & 0.687 & 0.006 & 25 & 0.007 & 0.935 & 0.007 & 0.937 & 0.018 \\
\hline 11 & 0.031 & 0.718 & 0.032 & 0.719 & 0.010 & 26 & 0.0 & 0.942 & 0.006 & 0.944 & 0.017 \\
\hline 12 & 0.028 & 0.746 & 0.029 & 0.747 & 0.013 & 27 & 0.0 & 48 & 0.006 & 0. & 0.016 \\
\hline 13 & 0.025 & 0.771 & 0.026 & 0. & 0.014 & 28 & & & & & 0.016 \\
\hline 14 & 0.023 & 0.794 & 0.023 & 0.796 & 0.015 & 29 & 0.005 & 0.958 & 0.005 & 0.959 & 0.015 \\
\hline
\end{tabular}

Table 1: Comparison of exact and simulated percentiles for an $M|M| 1$ queue

\section{SCENARIO RESULTS}

The estimated expected number of passengers occupying each platform for every hour of the operating day is shown in Figure 6 for current arrival estimations (Scenario 1), and a $25 \%$ decrease of inter-arrival times (Scenario 2 ). We did not test for statistically significant differences, as the numerical differences are large over several time periods.

The estimated passenger waiting times per platform and the daily average number of passengers waiting for the respective scenarios are shown in Table 2. The effect of passenger increase is clear: decreasing the arrival times by $25 \%$ results in an average increase of $37 \%$ in the waiting times and an $83 \%$ increase in the number of passengers waiting at Platform 1. (Note that Platform 3 is located opposite Platform 1, and Platform 2 and 4 form an opposite pair - see Figure 2)

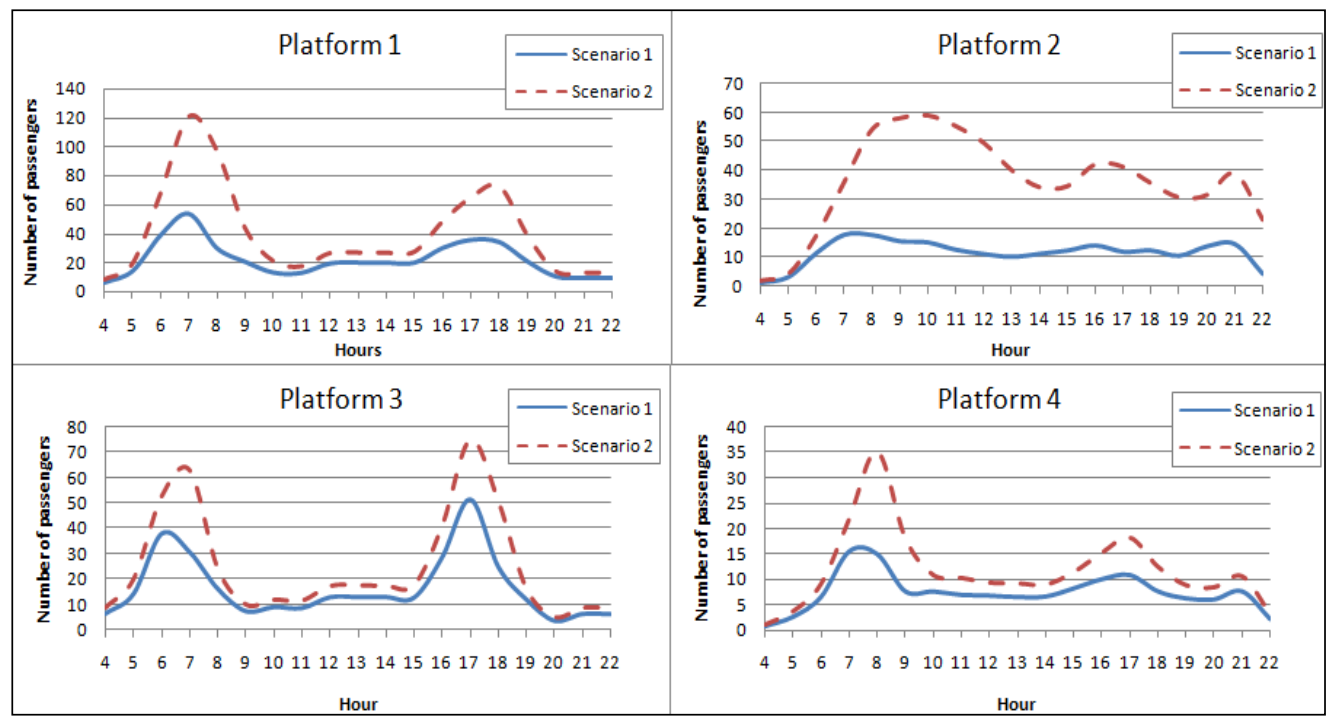

Figure 4: Estimated expected platform occupation for Scenario 1 and Scenario 2 


\begin{tabular}{|c|c|c|c|c|}
\hline \multicolumn{5}{|c|}{ Average waiting times at platforms (h) } \\
\hline & Platform 1 & Platform 3 & Platform 2 & Platform 4 \\
\hline Scenario 1 & 0.138 & 0.156 & 0.166 & 0.157 \\
\hline Scenario 2 & 0.199 & 0.178 & 0.386 & 0.186 \\
\hline \multicolumn{5}{|c|}{ Maximum waiting times at platforms (h) } \\
\hline \multicolumn{7}{|c|}{ Platform 1 } & Platform 3 & Platform 2 & Platform 4 \\
\hline Scenario 1 & 0.519 & 0.617 & 0.641 & 0.654 \\
\hline Scenario 2 & 0.638 & 0.646 & 1.082 & 0.741 \\
\hline \multicolumn{7}{|c|}{ Time weighted daily average number of passengers at platforms } \\
\hline Scenario 1 & Platform 1 & Platform 3 & Platform 2 & Platform 4 \\
\hline Scenario 2 & 22 & 17 & 12 & 8 \\
\hline
\end{tabular}

Table 2: Results for Scenario 1 and Scenario 2

One can also obtain the time frequencies for the daily number of passengers waiting. The cumulative frequency diagram of Platform 1 (Scenario 1) is shown in Figure 5, while the frequency duration of passenger presence on Platform 1 (Scenario 1) is shown in Table 3.

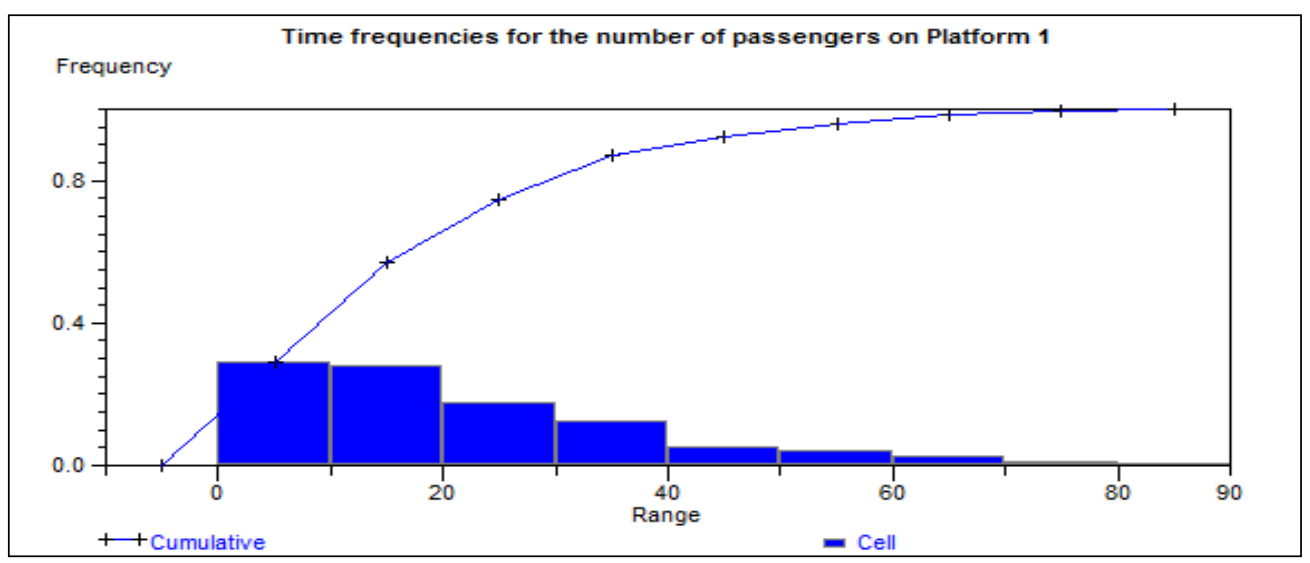

Figure 5: Cumulative time frequencies for Platform 1 (Scenario 1)

\begin{tabular}{|c|c|c|c|c|c|c|}
\hline \multicolumn{7}{|c|}{ Histogram Summary } \\
\hline \multicolumn{7}{|c|}{ Time frequencies for the number of passengers on Platform 1 } \\
\hline & \multicolumn{2}{|c|}{ Cell Limits } & \multicolumn{2}{|c|}{ Abs. Freq. (Time) } & \multicolumn{2}{c|}{ Rel. Freq. } \\
\hline Cell & From & To & Cell & Cumul. & Cell & Cumul. \\
\hline 1 & -Infinity & 0 & 0 & 0 & 0 & 0 \\
\hline 2 & 0 & 10 & 5.532 & 5.532 & 0.291 & 0.291 \\
\hline 3 & 10 & 20 & 5.300 & 10.830 & 0.279 & 0.570 \\
\hline 4 & 20 & 30 & 3.303 & 14.130 & 0.174 & 0.744 \\
\hline 5 & 30 & 40 & 2.381 & 16.520 & 0.125 & 0.870 \\
\hline 6 & 40 & 50 & 0.960 & 17.480 & 0.051 & 0.919 \\
\hline 7 & 50 & 60 & 0.755 & 18.230 & 0.039 & 0.959 \\
\hline 8 & 60 & 70 & 0.451 & 18.680 & 0.024 & 0.983 \\
\hline 9 & 70 & 80 & 0.191 & 18.870 & 0.010 & 0.993 \\
\hline 10 & 80 & +Infinity & 0.127 & 19.000 & 0.007 & 1.000 \\
\hline
\end{tabular}


From Table 3, the following can be deduced:

- For $57 \%$ of the operating time in a day, the occupation will range between 10 and 20 passengers. See tag (1) in Table 3.

- Platform 1 occupation ranges between 20 and 30 passengers for 3.303 hours of the day. See tag (2) in Table 3.

- For 16.52 hours of the 19 -hour day, the occupation will be less than 40 passengers. See tag (3) in Table 3.

A further interpretation is possible using the results in Table 4.

\begin{tabular}{|c|c|c|c|}
\hline $\begin{array}{c}\text { Platform 1 number } \\
\text { waiting }\end{array}$ & $\begin{array}{c}\text { Passenger } \\
\text { frequency }\end{array}$ & $\begin{array}{c}\text { Relative } \\
\text { frequency }\end{array}$ & $\begin{array}{c}\text { Cumulative } \\
\text { frequency }\end{array}$ \\
\hline $0<X \leq 10$ & 689 & 0.221 & 0.221 \\
\hline $10<X \leq 20$ & 626 & 0.201 & 0.422 \\
\hline $20<X \leq 30$ & 550 & 0.177 & 0.599 \\
\hline $30<X \leq 40$ & 460 & 0.148 & 0.746 \\
\hline $40<X \leq 50$ & 283 & 0.091 & 0.837 \\
\hline $50<X \leq 60$ & 247 & 0.079 & 0.917 \\
\hline $60<X \leq 70$ & 158 & 0.051 & 0.967 \\
\hline $70<X \leq 80$ & 61 & 0.020 & 0.987 \\
\hline $80<X$ & 41 & 0.013 & 1.000 \\
\hline
\end{tabular}

Table 4: Passenger frequencies for Platform 1 (Scenario 1)

The passenger frequencies show the number of observations (passengers) counted in the specified ranges. Valuable conclusions can be made by using the passenger frequencies together with the time frequencies. The following is an example for the range between 20 and 30 passengers:

- $\quad$ For $74.4 \%$ of the operating time (see Table 3), up to $59.9 \%$ (Table 4 ) of the total number of passengers made use of the service that day, where they will wait in a group comprising fewer than 30 passengers.

- Up to $59.9 \%$ of the total number of passengers will make use of the service $74.4 \%$ (see Table 3 ) of the operating time, where they will wait in a group comprising fewer than 30 passengers. This means the remainder of the expected passengers (40.1\%) will make use of the service in only $25.6 \%$ of the operating hours, which is $19-14.87=4.87$ hours of the day.

Results were also generated for the waiting areas of Platform 2, 3, and 4. As mentioned before, Platform 3 is located opposite Platform 1 at Thibault Station (see Figure 2), and Platform 2 and 4 form an opposite pair. Aggregated results for the two pairs of platforms were collected during the simulation runs (Platforms 1 and 3, Platforms 2 and 4), and the results can be used to design the aggregated capacity of the station. The combined observed response for the Platform 1-3 pair (Scenario 1) is shown in Figure 8 and Table 5 (Time frequencies). 


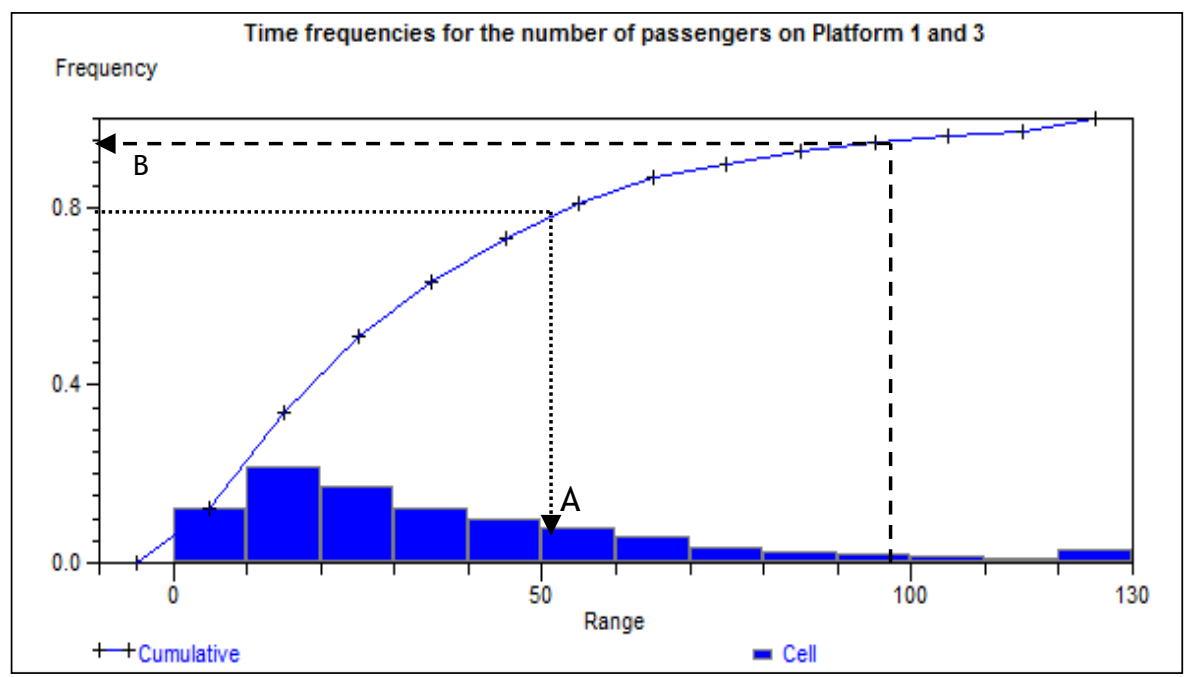

Figure 6: Cumulative time frequencies for the combined number of passengers on Platform 1 and Platform 3 (Scenario 1)

\begin{tabular}{|c|c|c|c|c|c|c|}
\hline \multicolumn{7}{|c|}{ Histogram Summary } \\
\hline \multicolumn{7}{|c|}{ Time frequencies for the number of passengers on Platform 1 and 3} \\
\hline & \multicolumn{2}{|c|}{ Cell Limits } & \multicolumn{2}{|c|}{ Abs. Freq. (Time) } & \multicolumn{2}{|c|}{ Rel. Freq. } \\
\hline Cell & From & To & Cell & Cumul. & Cell & Cumul. \\
\hline 1 & -Infinity & 0 & 0 & 0 & 0 & 0 \\
\hline 2 & 0 & 10 & 2.305 & 2.305 & 0.121 & 0.121 \\
\hline 3 & 10 & 20 & 4.145 & 6.449 & 0.218 & 0.339 \\
\hline 4 & 20 & 30 & 3.254 & 9.703 & 0.171 & 0.511 \\
\hline 5 & 30 & 40 & 2.310 & 12.010 & 0.122 & 0.632 \\
\hline 6 & 40 & 50 & 1.867 & 13.880 & 0.098 & 0.731 \\
\hline 7 & 50 & 60 & 1.498 & 15.380 & 0.079 & 0.809 \\
\hline 8 & 60 & 70 & 1.072 & 16.450 & 0.056 & 0.866 \\
\hline 9 & 70 & 80 & 0.637 & 17.090 & 0.033 & 0.899 \\
\hline 10 & 80 & 90 & 0.508 & 17.590 & 0.027 & 0.926 \\
\hline 11 & 90 & 100 & 0.377 & 17.970 & 0.019 & 0.946 \\
\hline 12 & 100 & 110 & 0.268 & 18.240 & 0.014 & 0.960 \\
\hline 13 & 110 & 120 & 0.227 & 18.470 & 0.012 & 0.972 \\
\hline 14 & 120 & +Infinity & 0.533 & 19.000 & 0.028 & 1.000 \\
\hline
\end{tabular}

Table 5: Time frequencies for the combined numbers of passengers on Platform 1 and Platform 3 (Scenario 1)

Table 6 shows the passenger frequencies for the combined number of passengers on Platform 1 and Platform 3 (Scenario 1). 


\begin{tabular}{|c|c|c|c|}
\hline $\begin{array}{c}\text { Platform 1 } \\
\text { number waiting }\end{array}$ & $\begin{array}{c}\text { Passenger } \\
\text { frequency }\end{array}$ & $\begin{array}{c}\text { Relative } \\
\text { frequency }\end{array}$ & $\begin{array}{c}\text { Cumulative } \\
\text { frequency }\end{array}$ \\
\hline $0<X \leq 10$ & 411 & 0.079 & 0.079 \\
\hline $10<X \leq 20$ & 606 & 0.117 & 0.196 \\
\hline $20<X \leq 30$ & 625 & 0.121 & 0.317 \\
\hline $30<X \leq 40$ & 598 & 0.115 & 0.432 \\
\hline $40<X \leq 50$ & 566 & 0.109 & 0.541 \\
\hline $50<X \leq 60$ & 518 & 0.100 & 0.641 \\
\hline $60<X \leq 70$ & 423 & 0.082 & 0.723 \\
\hline $70<X \leq 80$ & 332 & 0.064 & 0.787 \\
\hline $80<X \leq 90$ & 275 & 0.053 & 0.840 \\
\hline $90<X \leq 100$ & 217 & 0.042 & 0.882 \\
\hline $100<X \leq 110$ & 154 & 0.030 & 0.912 \\
\hline $110<X \leq 120$ & 131 & 0.025 & 0.937 \\
\hline $120<X$ & 327 & 0.063 & 1.000 \\
\hline
\end{tabular}

Table 6: Passenger frequencies for the combined number of passengers on Platform 1 and Platform 3 (Scenario 1)

Similar interpretations of the data given for the passenger count of Platform 1 hold for Figure 6 and Table 6; consider for example the cumulative line in Figure 6. Examples of how this information could be used as a basis for design decisions are as follows:

- Different alternatives can be weighed up against one another: for an area to accommodate passengers $80 \%$ of the operating time, the cumulative line shows that it must be designed and built to fit up to 60 passengers. For the other $20 \%$ of the time the area will not be able to accommodate the expected demand and these passengers will have to wait at alternative waiting areas. This is known as the 80th percentile at which the station is designed, and is illustrated in Figure 6 by the dotted line indicated as ' $A$ '. Knowing this information, the space requirements for that area can be calculated. Using values of standard practices taken from the Highway Capacity Manual 2000 [13], the basic minimum space requirement for a single standing passenger is determined at $0.3 \mathrm{~m}^{2}$. For a passenger facility, an area of $0.75 \mathrm{~m}^{2}$ is used as a buffer zone for each pedestrian. Using this figure, the space required to accommodate passengers $80 \%$ of the time would be $52 \times 0.75 \mathrm{~m}^{2}=39 \mathrm{~m}^{2}$.

- Conversely, the cumulative line could also be used to obtain information about the percentile for a specific space: if the proposed station is designed with a waiting area of $75 \mathrm{~m}^{2}$, the number of passengers it can hold is calculated as 100 passengers $\left(75 \mathrm{~m}^{2} \div 0.75 \mathrm{~m}^{2} /\right.$ passenger). Referring back to the graph in Figure 6, the cumulative line shows a 95th percentile (operating time) for 100 passengers. The dashed line labelled ' $B$ ' shows how this value can be read from the graph. This means that an area of $75 \mathrm{~m}^{2}$ will be sufficient to accommodate passengers $95 \%$ of the time.

There is a trade-off between the percentile for which a station is designed and the cost of the station. Is the designer going to design a station at the 80th percentile, which will be less expensive, and accommodate fewer passengers, or at the 95th percentile, which will accommodate more passengers? A larger percentile will require more space, which in turn increases the costs. These graphs are useful for such decisions, and more can be created using the proposed decision support model.

The information presented for Scenario 1 is valuable for decision-making purposes; however, it will also be valuable to compare Scenario 1 with Scenario 2 to see what impact a $25 \%$ difference in inter-arrival rates will have on the proposed station design - i.e., a busier process. The decision support model allows for exactly that: testing the sensitivity of the passenger estimates. 
The previous analysis for the waiting areas of Platform 1 and Platform 3 combined (Scenario 1) can be repeated for Scenario 2. The results of the time percentiles for Platform 1 and Platform 3 combined (Scenario 2) are presented in Figure 7 and Table 7.

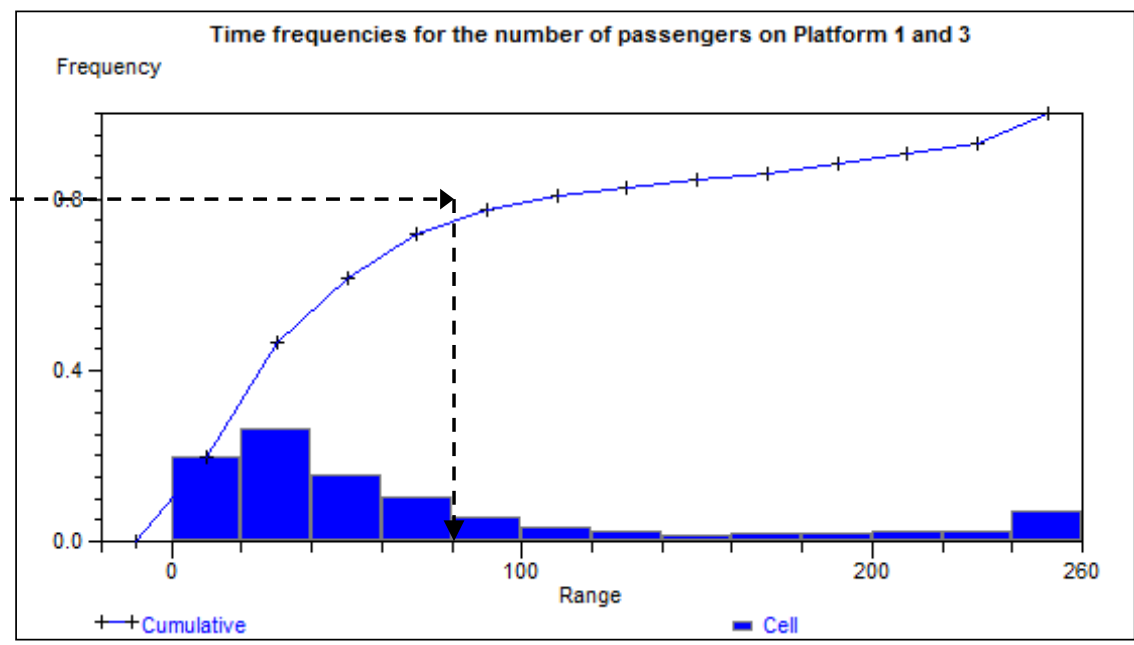

Figure 7: Cumulative time frequencies for the combined number of passengers on Platform 1 and Platform 3 (Scenario 2)

\begin{tabular}{|c|c|c|c|c|c|c|}
\hline \multicolumn{7}{|c|}{ Histogram Summary } \\
\hline \multicolumn{7}{|c|}{ Time frequencies for the number of passengers on Platform 1 and 3 } \\
\hline & \multicolumn{2}{|c|}{ Cell Limits } & \multicolumn{2}{|c|}{ Abs. Freq. (Time) } & \multicolumn{2}{c|}{ Rel. Freq. } \\
\hline Cell & From & To & Cell & Cumul. & Cell & Cumul. \\
\hline 1 & -Infinity & 0 & 0 & 0 & 0 & 0 \\
\hline 2 & 0 & 20 & 3.787 & 3.787 & 0.199 & 0.199 \\
\hline 3 & 20 & 40 & 5.01 & 8.797 & 0.264 & 0.463 \\
\hline 4 & 40 & 60 & 2.923 & 11.72 & 0.154 & 0.617 \\
\hline 5 & 60 & 80 & 1.949 & 13.67 & 0.103 & 0.719 \\
\hline 6 & 80 & 100 & 1.036 & 14.70 & 0.055 & 0.774 \\
\hline 7 & 100 & 120 & 0.598 & 15.30 & 0.031 & 0.805 \\
\hline 8 & 120 & 140 & 0.435 & 15.74 & 0.023 & 0.828 \\
\hline 9 & 140 & 160 & 0.301 & 16.04 & 0.015 & 0.844 \\
\hline 10 & 160 & 180 & 0.313 & 16.35 & 0.016 & 0.861 \\
\hline 11 & 180 & 200 & 0.384 & 16.74 & 0.020 & 0.882 \\
\hline 12 & 200 & 220 & 0.486 & 17.22 & 0.026 & 0.906 \\
\hline 13 & 220 & 240 & 0.477 & 17.70 & 0.025 & 0.932 \\
\hline 14 & 240 & + Infinity & 1.302 & 19.00 & 0.069 & 1.000 \\
\hline
\end{tabular}

Table 7: Time frequencies for the combined numbers of passengers on Platform 1 and 3 (Scenario 2)

Table 8 shows the passenger frequencies for Scenario 2 . 


\begin{tabular}{|c|c|c|c|}
\hline $\begin{array}{c}\text { Combined passenger count } \\
\text { for Platform 1 and 3 }\end{array}$ & $\begin{array}{c}\text { Passenger } \\
\text { frequency }\end{array}$ & $\begin{array}{c}\text { Relative } \\
\text { frequency }\end{array}$ & $\begin{array}{c}\text { Cumulative } \\
\text { frequency }\end{array}$ \\
\hline $0<X \leq 20$ & 723 & 0.11 & 0.11 \\
\hline $20<X \leq 40$ & 961 & 0.14 & 0.25 \\
\hline $40<X \leq 60$ & 857 & 0.12 & 0.37 \\
\hline $60<X \leq 80$ & 687 & 0.10 & 0.47 \\
\hline $80<X \leq 100$ & 463 & 0.07 & 0.54 \\
\hline $100<X \leq 120$ & 380 & 0.06 & 0.59 \\
\hline $120<X \leq 140$ & 313 & 0.05 & 0.64 \\
\hline $140<X \leq 160$ & 210 & 0.03 & 0.67 \\
\hline $160<X \leq 180$ & 226 & 0.03 & 0.70 \\
\hline $180<X \leq 200$ & 284 & 0.04 & 0.74 \\
\hline $200<X \leq 220$ & 268 & 0.05 & 0.80 \\
\hline $220<X \leq 240$ & 352 & 0.05 & 0.85 \\
\hline $240<X$ & 1028 & 0.15 & 1.00 \\
\hline
\end{tabular}

Table 8: Passenger frequencies for the combined number of passengers on Platform 1 and Platform 3 (Scenario 2)

The $80^{\text {th }}$ time percentile for Scenario 1 requires an area that holds up to 52 passengers. The $80^{\text {th }}$ time percentile for Scenario 2 (Figure 7) requires an area that holds between 100 and 120 passengers. There is a vast difference between the two scenarios. If the station was built according to Scenario 1 and the passenger estimates were incorrect, the impact could be very negative for the same number of buses.

The scenarios were constructed to investigate the effect the variation would have on the performance of the system. More importantly, it also showed how the decision support model can be used as a tool to investigate and evaluate many different aspects relating to the capacity of a station.

This method generates easily understandable graphs that display significant information about the performance measurements of a system, the impacts that might be experienced, and the capacity capabilities for different parameters. Outcomes of scenarios can be generated with relative ease, investigated, and compared against each another.

\section{CONCLUSION}

This paper presented a decision support model for capacity estimations of BRT stations. A case study of Thibault Station in Cape Town, South Africa, was presented and showed how this model can be used to investigate capacity parameters for the station. The model delivers useful design measures, such as the average number of passengers per waiting area, the average waiting times, and the frequencies and percentiles of passenger counts.

Through the scenarios presented in the case study, it is possible to affirm the purpose and usefulness of the model. The model offers a variety of options to its users, giving them control over investigations to create concrete evidence for design decision support. The direct implications of the proposed decision support model are:

- $\quad$ users are able to define input data for the model to suit the specifications of the station they are investigating;

- $\quad$ the performance of a station can be predicted for different scenarios; and

- capacity parameters can be analysed.

We have demonstrated the need to estimate percentiles when doing simulation studies, because that type of output parameter affords the decision maker more information than point estimators of the mean. 


\section{FUTURE RESEARCH}

The following suggestions are made for future work:

- Building a corridor by replicating the simulation model:

The model developed in this study can be used as a basis for expanding the simulation model into an entire BRT corridor, consisting of more than one station. The model can be duplicated and linked, on which numerous capacity studies could be done.

- Integrating a bus schedule into the simulation model:

This study did not focus on implementing a bus schedule into the simulation model, as a schedule was provided by the designers. A mathematical programming technique can be used to develop an optimal bus schedule. This could then be linked to the simulation model on which further investigations could be done, such as the costs related to the optimal bus schedule requirements versus its efficiency.

- Developing a fully generic stochastic simulation model:

The current stochastic model is based on the station configuration of Thibault Station, i.e. four platforms and four waiting areas. Model adjustments would need to be made for other station configurations. The same holds for the input data spreadsheets that were developed for the model. Although the spreadsheets are user-friendly and values are easily adjustable, the bus schedule spreadsheets are designed for a cycle consisting of four station stops in a cycle. For a cycle consisting of fewer or more station stops, MS Excel and Arena adjustments are needed. A more generic approach could be valuable in future studies.

\section{REFERENCES}

[1] Chen, E.J. \& Kelton, W.D. 2006. Quantile and tolerance-interval estimation in simulation, European Journal of Operational Research, 168(2), pp 520-540.

[2] Fruin, J.J. 1971. Pedestrian planning and design. Metropolitan Association of Urban Designers and Environmental Planners.

[3] Iglehart, D.L. 1976. Simulating stable stochastic systems; VI. quantile estimation, Journal of the Association for Computing Machinery, 23, pp 347-360.

[4] Institute for Transportation \& Development policy, New York, http://www.itdp.org/. Accessed 8 February 2011.

[5] Kittelson \& Associates, Inc. 1999. TCRP web document 6 - Transit capacity and quality of service manual. Transportation Research Board, National Research Council.

[6] Law, A.M. \& Kelton, W.D. 2000. Simulation modeling and analysis, $3^{\text {rd }}$ edition, McGraw-Hill.

[7] Lieberman, E. \& Rathi, A.K. 1975. TRB Special Report 165 Traffic Flow Theory, Transportation Research Board.

[8] Raatikainen, K.E.E. 1990. Sequential procedure for simultaneous estimation of several percentiles, Transactions of the Society for Computer Simulation, 7(1), pp 21-44.

[9] Sabra, Z., Wallace, C.E. \& Lin, F. 2000. Traffic analysis software tools, Transportation Research Board, pp 12-16.

[10] Schriber, T.J. \& Brunner, D.T. 2005. Inside discrete-event simulation software: How it works and why it matters, in Proceedings of the 2005 Winter Simulation Conference, (M.E. Kuhl, N.M. Steiger, F.B. Armstrong \& J.A. Joines, eds), Simulation Society of INFORMS, www.informssim.org, pp 167-177.

[11] Seila, A.F. 1982. A batching approach to quantile estimation in regenerative simulations, Management Science, 28(5), pp 573-581.

[12] The American Heritage Dictionary of the English Language. 2003. U.w. 'traffic congestion'. Houghton Mifflin.

[13] Transportation Research Board. 2000. Highway capacity manual 2000, National Research Council.

[14] Wright, L. \& Hook, W. 2007. Bus rapid transit planning guide. Institute for Transportation and Development Policy, p. 48.

[15] Yang, F., Ankenman, B.E. \& Nelson, B.L. 2008. Estimating cycle time percentile curves for manufacturing systems via simulation, INFORMS Journal on Computing, 20, pp 628-643. 